\title{
COMPLAINTS ROOT CAUSE ANALYSIS AS A PART OF THE MEDICAL DEVICES QUALITY IMPROVEMENT PROCESS
}

\author{
Aleksandra ZIARKIEWICZ ${ }^{1 *}$, Justyna GÓRNA ${ }^{2}$ \\ ${ }^{1}$ Uniwersytet Ekonomiczny, Poznań; aleksandra.ziarkiewicz@phd.ue.poznan.pl \\ ${ }^{2}$ Uniwersytet Ekonomiczny, Poznań; justyna.gorna@ue.poznan.pl, ORCID: 0000-0002-2763-5810 \\ * Correspondence author
}

Purpose: The purpose of the paper is to present the essence of the complaint handling process as an element of the process of improving the quality of manufactured medical devices, ensuring their safety of use and meeting the declared by the manufacturer efficiency of the medical devices. Detailed analysis of complaints received from the customers in order to identify the root cause of the reported problems allows initiating the appropriate actions by the company. The remedial actions are designed to eliminate defects reported by customers, while the corrective actions are carried out to eliminate the causes of the reported defects. All these actions taken by the company in course of the complaint handling process are the important element influencing not only the effectiveness of the complaint handling process but also improvement of the product, elimination of defects, and thus the safe use of the device by the user.

Design/methodology/approach: The analysis of the main causes of the reported failures and actions taken was conducted through a survey questionnaire forwarded to 24 medical device manufacturers in Poland.

Findings: The results of this survey allowed to identify the categories of root causes, which are the most frequent reasons for complaints concerning medical devices and to identify the most frequent corrections and corrective actions based on the example of selected companies manufacturing medical devices in Poland.

Originality/value: The results of the survey regarding the main causes of the reported failures and actions taken during the complaint handling process may provide guidance for the manufacturers during the evaluation of the reported failures.

Keywords: complaint, medical devices, root cause, remedial action, corrective action.

\section{Introduction}

The production of medical devices is a highly diversified industry. Not only in terms of the variety of products classified as medical devices and the requirements for placing these devices on the market, but also in terms of the wide range of customers - from individual users to 
hospitals and care facilities. Medical devices play a significant role in the health and life of users. This group of devices includes both simple devices such as wheelchairs or surgical gloves, and more complex devices that pose a high risk due to their use, such as stents or hip dentures (Medical Devices: Managing the Mismatch: An outcome of the Priority Medical Devices project, 2018). According to the regulation, a medical device ("Regulation (EU) 2017/745 of European Parliament and of the Council of 5 April 2017 on medical devices, amending Directive 2001/83/EC, Regulation (EC) No 178/2002 and Regulation (EC) No 1223/2009 and repealing Council Directives 90/385/EEC and 93/42/EEC”) is defined as: "any instrument, apparatus, appliance, software, implant, reagent, material or other article intended by the manufacturer to be used, alone or in combination, for human beings for one or more of the following specific medical purposes: - diagnosis, prevention, monitoring, prediction, prognosis, treatment or alleviation of disease, - diagnosis, monitoring, treatment, alleviation of, or compensation for, an injury or disability, - investigation, replacement or modification of the anatomy or of a physiological or pathological process or state, - providing information by means of in vitro examination of specimens derived from the human body, including organ, blood and tissue donations, and which does not achieve its principal intended action by pharmacological, immunological or metabolic means, in or on the human body, but which may be assisted in its function by such means. The following products shall also be deemed to be medical devices: - devices for the control or support of conception; - products specifically intended for the cleaning, disinfection or sterilization of devices as referred to in Article 1(4) and of those referred to in the first paragraph of this point".

Based on the above-mentioned definition of the medical device and the described functionalities, it can be concluded that they play a significant role and that their use is associated with a direct risk for the user. For this reason, it is important to ensure that the medical device placed on the market is safe and meets the declared manufacturer's performance specification. One of the processes that allow the monitoring and improvement of medical devices quality is the complaint handling process.

Complaints received from the customers may be a source of information used to improve the quality of devices and improve the production process. Appropriate analysis of the problem by identifying the source cause may allow to identify the reason for customer dissatisfaction and allows to take appropriate actions that would eliminate the identified problem and prevent its recurrence (Olszewska, 2012). The ISO 9000: 2015 standard defines a complaint as an expression of a customer's dissatisfaction with a product, service or the process of dealing with complaints, where a response or resolution is explicitly or implicitly expected. On the other hand, ISO 13485: 2016 defines the scope of the complaint as: "written, electronic or oral communication that alleges deficiencies related to the identity, quality, durability, reliability, usability, safety or performance of a medical device that has been released from the organization's control or related to a service that affects the performance of such medical devices". One of the important stages of the complaint handling process is the step concerning 
the analysis of information from the customer in order to determine the root cause of the reported problem, taking into account the deficiencies described in the above definition.

There are different sources of customer complaints. They can be submitted via e-mail, online contact forms, telephones, social media or traditional letters sent by post. Frequently, complaints are issued directly by customers, but they can also be filed second-hand by customer service personnel, the sales team or maintenance personnel. The research has shown that about $2 / 3$ of all complaints are filed over the phone. The main reason is the need to report an identified problem directly to a specific person. This ensures that customers may be confident that the complaint will be accepted and registered. Telephone conversations are often also better for a representative of the company, as they can then receive more information about a given defect, which allows for a more accurate analysis of the problems ("Understanding the basics").

\section{Root cause analysis}

Complaints that result from releasing defective devices to the customers by manufacturers can result in serious consequences. In the case of such critical products as medical devices, the release of a defective device to the customer may have an impact on the health and life of their users. The smallest mistake made by the manufacturer may lead to serious consequences, therefore it is important to detect and eliminate errors made at the manufacturing phase before the device leaves the factory. However, if there is a situation in which the defective product is delivered to the customer, the complaint is one of the ways to eliminate this problem and make sure that it does not occur in the future. It should also be stressed that any complaint from a customer, where an error is identified to be due to the manufacturer's fault, generates additional costs for the company and affects the loss of trust in the brand.

After receiving information from the customer, the complaint is registered by the company in the local system and assigned to a proper person who will be responsible for handling the complaint. All information received from the customer is then reviewed to ensure that the data collected are sufficient for further analysis. In case of missing information, a representative of the company may contact the customer for additional details. The analysis of problems reported by customers is an important step in the process of complaint handling. In accordance with the diagram below (Figure 1.), the purpose of this phase is to collect detailed information about the reported problem and its analysis, which leads to the identification of the root cause of the reported problem and, at a later stage, to take appropriate corrective actions that will eliminate the reported problem and prevent its recurrence in the future ("Guidelines on complaint handling", 2017). 


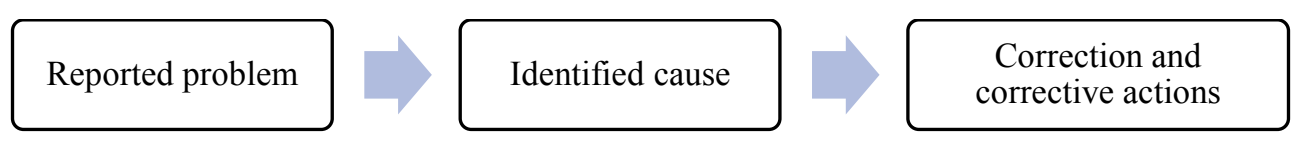

Figure 1. Diagram of root cause analysis. Adapted from: "Guidelines on complaint handling, Ombudsman", Western Australia, 2017.

In order to identify the potential root cause of the problem, specific tools and techniques can be used. They include, among others:

- brainstorming - this method allows to generate a variety of ideas through the possibility of free speech by the participants. Through the discussion, new, innovative ideas can be created in a short time. The more people take part in a brainstorming session, the more ideas can be brought up. Often brainstorming is the first stage of analysis, where different categories of possible root causes are collected and then they are analysed in detail using other tools (Gołaś, and Mazur, 2010).

- $5 \mathrm{x}$ method - the method consists of asking a few questions starting with the phrase "why?" (their number does not have to be limited to 5), which are intended to lead to the identification of the root cause. Two aspects need to be taken into account when applying this method. The first one is the analysis of why the reported problem arose. The second aspect is to ask why the defective product has been released to the customer and the defect has not been detected before delivery. This method is common because it is simple and easy to use (Krajnc, 2012).

- Ishikawa Diagram - cause and effect diagram used to identify and illustrate potential causes in several different categories. The diagram consists of several parts: a specific problem, groups of causes that may have an impact on the problem, specific causes located in particular groups. The most common categories of causes are: man, machine, material, method, management, environment. After preparing the diagram, the presented results are analysed in details, which leads to the determination of the most probable causes, taking into account the reported problem. This method should be used by a team of experts from various departments, which allows for in-depth analysis of different categories (Czerwińska, and Pacana, 2012).

- $8 \mathrm{D}$ report - this method utilizes a structured eight-step approach to problem-solving. The main purpose is to address the problem and discover the weaknesses that may have led to the problem. The analysis is carried out in the following steps: setting up a team, identifying the problem, introducing immediate actions, verifying the root cause, identifying corrective actions, carrying out corrective actions, carrying out preventive actions, completing the actions. These steps and results are described in the $8 \mathrm{D}$ report (Krajnc, 2012). 
- FMEA (Causes and Effects of Defects Analysis) - this method identifies and assesses a potential problem, as well as the causes associated with it, which may have a significant impact on the reported defect. The result of the FMEA method is a risk assessment related to the occurrence of non-compliance, which is carried out by means of a risk assessment for each of the previously identified causes. The next step of the analysis is to propose measures and to review their effectiveness (Krajnc, 2012).

Once the root cause has been identified, a correction, i.e. an action that will eliminate the reported defect, should be made. An example of correction can be e.g.: replacement of a product with a new one or its repair. The identified root cause also results in the introduction of corrective actions to eliminate the possibility of receiving further complaints concerning the reported defect.

The last step is to confirm that the implemented actions are effective. In order to check this, companies monitor all reported complaints. If a new complaint is not registered within a certain period of time, it means that the company has introduced appropriate corrective measures, which are effective. However, if there are further complaints related to the same defect, the company should resume the analysis in order to check other possible causes of the problem (Menon, Kamath, Shabaraya, 2016).

\section{The key root causes of complaints and the most frequently undertaken corrections and corrective actions - questionnaire survey}

In order to identify the most important categories of causes of complaints and to determine the most frequently undertaken categories of corrections and corrective actions, a questionnaire survey was carried out. The subject of the survey were 24 companies manufacturing medical devices in Poland. The surveyed companies had a certificate of compliance with the quality management system in accordance with the requirements of ISO 13485. These companies manufactured medical devices of various classes - from class I (devices with the lowest risk related to their use) to class III (the highest risk).

The root cause categories have been identified on the basis of a literature analysis as well as with the assistance of experts dealing with the complaint handling process in companies manufacturing medical devices. In order to assess the frequency of root cause categories, a 5-point scale was used, from 1 to 5, in which the following interpretation was used:

- 1 means never: 0 complaints per year,

- $\quad 2$ - rare: $1-10 \%$ of all complaints per year,

- 3- sometimes: $11-30 \%$ of all complaints within one year,

- 4 - often: $31-60 \%$ of all complaints during the year,

- $\quad 5$ - very often: $>60 \%$ of all complaints during the year. 
The results obtained during the survey are presented in the table below (Table 1).

Table 1.

Results of frequency evaluation of selected categories of root causes

\begin{tabular}{|c|c|c|c|c|c|}
\hline \multirow{2}{*}{ Root cause categories } & \multicolumn{5}{|c|}{ Frequency } \\
\hline & 1 & 2 & 3 & 4 & 5 \\
\hline production line operator error & & $25 \%$ & $25 \%$ & $25 \%$ & $25 \%$ \\
\hline defective component, raw materials supplied by the supplier & & $25 \%$ & $50 \%$ & $25 \%$ & \\
\hline manufacturing error (machines, tools) & & $50 \%$ & $37 \%$ & $13 \%$ & \\
\hline incorrect installation or repair of the device & $12 \%$ & $50 \%$ & $38 \%$ & & \\
\hline incorrect device design & $13 \%$ & $74 \%$ & $13 \%$ & & \\
\hline transport damage & $25 \%$ & $62 \%$ & $13 \%$ & & \\
\hline incorrect packaging method & $38 \%$ & $50 \%$ & $12 \%$ & & \\
\hline $\begin{array}{l}\text { inadequate storage conditions of the finished device (humidity, } \\
\text { temperature, etc.) }\end{array}$ & $38 \%$ & $50 \%$ & $12 \%$ & & \\
\hline incorrect labelling of the device & $38 \%$ & $62 \%$ & & & \\
\hline
\end{tabular}

Source: own study.

According to the results obtained, production errors are the most frequently identified root causes of problems reported in complaints. The mistakes of production line operators were the only ones identified by $25 \%$ of respondents as causing more than $60 \%$ of all complaints received during the year. Defective components, raw materials delivered by the supplier as well as production errors caused by machines or tools have also been identified by companies as one of the most common source causes. It can also be noted that all respondents defined the frequency of the first three categories of causes at a level of at least rarely (1-10\% of all complaints per year). On the basis of the results, it can be concluded that the least frequently identified category of root causes is incorrect labelling of devices, which does not constitute more than $10 \%$ of complaints during the year.

Another question in the questionnaire concerned the determination of the most frequently undertaken type of correction and corrective actions resulting from received complaints. These actions were also identified on the basis of an earlier literature review and expert knowledge. The results are presented in Table 2 and Table 3. According to the respondents' answers, the most frequently undertaken correction is additional quality control, which was indicated by $35 \%$ of the respondents. The most frequently identified corrections were: stopping the release of devices for delivery, separation of non-compliant devices, customer service activities and replacement of a defective product with a new one. Such responses were provided by $13 \%$ of respondents. It should be noted that some categories of presented corrections were not indicated as the most frequent actions taken by any of the respondents. These were such types of corrections as e.g. withdrawal of the product from the market or additional laboratory tests. 
Table 2.

Corrections most frequently performed according to respondents

\begin{tabular}{|l|c|}
\hline \multicolumn{1}{|c|}{ Type of correction category } & Percentage of responses \\
\hline additional quality control & $35 \%$ \\
\hline stopping the release of devices for delivery & $13 \%$ \\
\hline separation of non-compliant devices/components found & $13 \%$ \\
\hline service activities at the customer's site & $13 \%$ \\
\hline replacement of a defective device with a new one & $13 \%$ \\
\hline production line audit & $13 \%$ \\
\hline $\begin{array}{l}\text { inspection of manufactured finished devices of the same type throughout the } \\
\text { entire supply chain (warehouse in the manufacturing company, in transport, } \\
\text { in a warehouse in the distribution centre and/or at the customer's site) }\end{array}$ & $0 \%$ \\
\hline $\begin{array}{l}\text { withdrawal of a device from the market } \\
\text { control of finished devices of a different type produced on the same } \\
\text { production line as the non-compliant device }\end{array}$ & $0 \%$ \\
\hline additional laboratory tests & $0 \%$ \\
\hline
\end{tabular}

Source: own study.

Only two actions were indicated as the most frequently undertaken corrective actions: training for production employees (63\% of respondents responded this way) and update of work instructions (37\% of answers given). Twelve other activities were not indicated as the most frequently undertaken.

\section{Table 3.}

Corrective actions most frequently performed according to respondents

\begin{tabular}{|l|c|}
\hline \multicolumn{1}{|c|}{ Type of corrective action } & Percentage of responses \\
\hline training for production operators & $63 \%$ \\
\hline updating the work instructions & $37 \%$ \\
\hline engineering change & $0 \%$ \\
\hline calibration of the control and measurement equipment used & $0 \%$ \\
\hline change of machine parameters & $0 \%$ \\
\hline change in the order of operations at the workstation & $0 \%$ \\
\hline change of device manufacturing technology & $0 \%$ \\
\hline the introduction of additional control points on the production line & $0 \%$ \\
\hline complaint to the component's supplier & $0 \%$ \\
\hline defining and carrying out corrective actions at the supplier's site & $0 \%$ \\
\hline audit at the supplier site & $0 \%$ \\
\hline updating the risk analysis document & $0 \%$ \\
\hline modification of devices of the same type present on the market & $0 \%$ \\
\hline withdrawal of devices of the same type from the market & $0 \%$ \\
\hline
\end{tabular}

Source: own study.

\section{Summary}

On the basis of the conducted surveys, it was noticed that the main reason for the reported defects are errors occurring at the stage of medical device manufacturing. These include errors caused by the machine or the tools used in the production process, as well as errors resulting from mistakes made by operators. It should also be emphasized that defective components 
shipped by the supplier, used during assembly / production of the device may also result in the release of the non-compliant device to the market or the appearance of a defect during use of the device.

The results of the survey showed that the main corrections and corrective actions taken by companies are closely related to the indicated most common categories of causes. The most frequently undertaken correction is additional quality control, whereas the most frequently undertaken corrective action is training for production operators. These results may provide guidance during evaluation of the reported failures.

A detailed analysis of all the information concerning the reported defect, as well as checking whether a similar complaint has not already been registered, are the key elements starting the process of dealing with complaints. Thanks to them it is possible to identify the main causes and to carry out actions that will not only eliminate the reported problem, but also ensure that it will not reoccur in the future, which is the main objective of an effective complaint handling process. This is particularly important in the case of medical devices, which play a key role in people's health and life.

\section{References}

1. Czerwińska K., Pacana A. (2012). Zastosowanie narzędzi zarządzania jakością do analizy przyczyn wadliwości wyrobu. Zeszyty Naukowe Politechniki Śląskiej, Seria: Organizacja i Zarządzanie, 117, 424- 429.

2. Gołaś, H., Mazur, A. (2010). Zasady, metody i techniki wykorzystywane $w$ zarzadzaniu jakością. Politechnika Poznańska.

3. Guidelines on complaint handling (2017). Western Australia: Ombudsman.

4. Krajnc, M. (2012). With 8D method to excellent quality. Journal of Universal Excellence, 3, 119-122.

5. Medical device complaint handling: Understanding the basics, https://www.orielstat.com/ blog/medical-device-complaint-handling-understanding-basics/, 20.02.2018,

6. Medical Devices: Managing the Mismatch: An outcome of the Priority Medical Devices project (2018). World Health Organization.

7. Menon, M., Kamath, K., Shabaraya, A.R. (2016). Conducting root cause analysis and its implementation: A perspective. Manipal Journal of Pharmaceutical Sciences, 2, 2, 22-24.

8. Olszewska, B., Szewczyk, P. (2012). Skuteczne i efektywne zarządzanie reklamacjami na przykładzie wybranego przedsiębiorstwa. Zeszyty Naukowe Politechniki Śląskiej, 63a, 276. 
9. Regulation (EU) 2017/745 of European Parliament and of the Council of 5 April 2017 on medical devices, amending Directive 2001/83/EC, Regulation (EC) No 178/2002 and Regulation (EC) No 1223/2009 and repealing Council Directives 90/385/EEC and 93/42/EEC.

10. PN EN ISO 9000:2015 Systemy zarządzania jakością - Podstawy i terminologia.

11. PN EN ISO 13485:2016 Medical devices - Quality management systems - Requirements for regulatory purposes. 